Research Article

\title{
Aripiprazole-induced seizures in children with autism spectrum disorder and epilepsy
}

\author{
Mohammed MS Jan* \\ Professor and Consultant, Pediatric Neurology, Department of Pediatrics, Faculty of Medicine, King \\ AbdulAziz University, P O Box 80215, Jeddah 21589, Kingdom of Saudi Arabia
}

\section{Abstract}

Purpose: Children with autism spectrum disorder are at an increased risk for developing seizures, which can be triggered by classical antipsychotics. Aripiprazole is an atypical antipsychotic that has a safer drug profile. The objective is to present the experience with seizure control in autistic children who are placed on Aripiprazole.

Methods: Series of consecutive autistic children with comorbid epilepsy treated with Aripiprazole were identified prospectively over a 3-year period. Monthly follow up by one pediatric neurologist was performed to document seizure control.

Results: 56 autistic children with comorbid epilepsy were placed on Aripiprazole. Most children (59\%) were seizure free for at least 6 months. The initial Aripiprazole dose was $5 \mathrm{mg}$ in all patients. Follow up ranged between 5-8 months (mean 6.9). A total of 5 (9\%) children developed seizure provocation $(3 / 5)$ or worsening seizure control $(2 / 5)$. There were 3 males and 2 females with ages ranging between 6-11.5 years (mean 8.5). Three of these children had a previous history of seizure worsening with other antipsychotic drugs (respiridone in 2 and haloperidol in 1). One child with seizure provocation developed status epilepticus 5 days after introducing Aripiprazole that required intensive care admission. The drug was stopped in all 5 children with no long-term effects.

Conclusion: Seizure provocation or worsening seizure control is not uncommon following the introduction of Aripiprazole in autistic children with controlled epilepsy. Although the risk is low, parents should be warned and advised on what to do, particularly in the first month of therapy.

\section{Introduction}

Autism spectrum disorder (ASD) is a relatively common neurodevelopmental disorder associated with significant behavioral features [1]. Epilepsy, seizures and/or epileptiform activity on electroencephalography (EEG) are common comorbidities in children with ASD confirming the neurobiologic nature of the disorder [2]. Seizures may be provoked or have a worsened control by the co-administration of classical antipsychotics that are often used to help control associated behavioral abnormalities in autistic children [3]. Aripiprazole (trade names Zolinda or Abilify) is a unique atypical antipsychotic medication that is gaining popularity for use in children with autism spectrum disorder to treat associated behavioral features [4]. It is a partial dopamine D [2], serotonin 5-hydroxytryptamine (1A) receptor agonist,

\section{More Information}

*Address for Correspondence: Mohammed MS Jan, Professor and Consultant, Pediatric Neurology, Department of Pediatrics, Faculty of Medicine, King AbdulAziz University, P O Box 80215, Jeddah 21589, Kingdom of Saudi Arabia, Tel: 996-12-6401000 (ext. 20208); Fax: 996-12-6403975; Email: mmjan@kau.edu.sa; mohammedmsjan@yahoo.com

Submitted: 12 December 2019

Approved: 30 January 2020

Published: 31 January 2020

How to cite this article: Jan MMS. Aripiprazoleinduced seizures in children with autism spectrum disorder and epilepsy. J Adv Pediatr Child Health. 2020; 3: 008-010.

DOI: dx.doi.org/10.29328/journal.japch.1001009

Copyright: () 2020 Jan MMS. This is an open access article distributed under the Creative Commons Attribution License, which permits unrestricted use, distribution, and reproduction in any medium, provided the original work is properly cited.

Keywords: Aripiprazole; Seizure; Epilepsy; Child; Side effect; Autism

(W) Check for updates

OPEN ACCESS and 5-hydroxytryptamine (2A) receptor antagonist. It is also effective in treating abnormal behavior associated with a number of other childhood psychiatric disorders, including schizophrenia, bipolar disorder, and other behavioral problems [4]. Aripiprazole has a safer drug profile compared with other antipsychotic medications, such as haloperidol or respiridone, with regard to its effect on weight, glucose tolerance, prolactin level, cardiac conduction, and most importantly epilepsy [5]. It is not typically associated with an increased risk of seizure provocation such as the other antipsychotics. The most common neurological adverse effects include headache, agitation, insomnia, sleepiness, and extrapyramidal symptoms, specifically dystonia, parkinsonism, akathisia, and dyskinesia. Seizures have been very rarely reported [6]. 
In this paper I present our experience with seizure provocation or worsening seizure control in children with autism spectrum disorder and epilepsy who are placed on Aripiprazole.

\section{Methods}

A series of consecutive children with autism spectrum disorder and comorbid epilepsy treated with Aripiprazole were identified prospectively over a 3-year period ending the $1^{\text {st }}$ of July, 2018. Patients were identified through referrals to the pediatric neurology services at King Abdulaziz University Hospital (KAUH) and the Saudi German Hospital (SGH), Jeddah, Saudi Arabia. Both are multispecialty adult and pediatric hospitals providing tertiary medical care for a regional population of western Saudi Arabia. The author covers the pediatric neurology services in both institutions.

Patients receiving Aripiprazole as the only antipsychotic for treating abnormal behavior and aggression were included. Aripiprazole initial dose was not to exceed $5 \mathrm{mg}$ /day or 0.5 $\mathrm{mg} / \mathrm{kg} /$ day. The dose was doubled every month until the minimum effective dose was reached (parental satisfaction with improved behavior using a checklist) or up to a maximum dose of $15 \mathrm{mg} /$ day. The risk of drug-induced seizures was explained to all parents as very small based on the available literature. Monthly follow up by one pediatric neurologist was performed to document the outcome. Minimum follow-up duration of 6 months was required to be included in the study. Seizure diaries were used to document seizure control. If patient's seizures were controlled for at least 6 months before initiating Aripiprazole and then developed within the first 4 weeks following its introduction, it is considered seizure "provocation". The treating physician should have documented this during a hospital or clinic visits. Seizure "worsening" was defined as increased seizures by at least $50 \%$ in duration or frequency, or occurrence of status epilepticus unrelated to an identifiable trigger or illness within the first 4 weeks of introducing Aripiprazole. Clinical course and outcome data were collected on follow-up visit or hospitalization records if required.

\section{Results}

During the study period, 56 autistic children with comorbid epilepsy were placed on Aripiprazole. Their epilepsy was controlled on 1-2 antiepileptic drugs. Most children (59\%) were completely seizure free for at least 6 months before introducing Aripiprazole. The remaining patients had rather infrequent seizures, and none had daily attacks. The most commonly used AEDs were Levitiracetam, Valproic acid, carbamazepine, and topiramate. Partial seizures were the most common type of seizures in these children $(41 / 56)$. The etiology in these children was not known and none had symptomatic brain abnormalities. Brain MRI was normal or showed non-specific changes in all children. EEG revealed focal epileptiform discharges in $86 \%$, most commonly temporal or frontal.
Before starting Aripiprazole, most children (73\%) were tried on other antipsychotics with no response or with excessive side effects, most commonly sedation. This resulted in drug weaning and placement on Aripiprazole. The initial Aripiprazole dose was $5 \mathrm{mg}$ in all patients. Follow up ranged between 5-8 months (mean 6.9). A total of 5 (9\%) children developed seizure provocation $(3 / 5)$ or worsening seizure control $(2 / 5)$ following the introduction of Aripiprazole (Table 1). There were 3 males and 2 females with ages ranging between 6-11.5 years (mean 8.5). Three of these children had a previous history of seizure worsening to other antipsychotic drugs (respiridone in 2 and haloperidol in 1). One of the children with seizure provocation developed status epilepticus 5 days after introducing Aripiprazole that required intensive care admission. The drug was stopped in all 5 children with no long-term effects on their seizure control.

\section{Discussion}

The patients described herein confirm that Aripiprazolerelated seizure provocation or worsening in children with autism spectrum disorder and comorbid epilepsy is more common than once recognized [7]. This is true even if the seizures were well controlled as noted in our study patients. Although the risk is low (9\%), it can be significant as one of our patients developed status epilepticus that required a brief intensive care admission. Parents should be warned about this risk and advised on what to do, particularly during the first month of therapy. It is theoretically possible that this risk is even higher in patients with poorly controlled seizures. However, this requires additional study. This risk is of a significant concern because of the inherit risk of epilepsy in children with autism spectrum disorder, particularly as they advance in age [8].

We used a small initial dose and titrated Aripiprazole very slowly. It is possible that higher initial doses or faster titration may be associated with higher risk. This is suggested recently in a reported case of a 3 year old child who accidentally ingested $30 \mathrm{mg}$ of Aripiprazole and developed subsequent seizures [6]. Further study of this issue is needed using larger patient populations and preferably multicenter studies to help look for significant associations. For example, we found that children with a previous history of seizure worsening to other antipsychotic drugs, which are known to be pro-convulsive [9], were at higher seizure risk following the introduction of Aripiprazole. Our sample was too small to identify statistically significant associations. However, we advice more caution is needed in these children.

\begin{tabular}{|l|c|c|c|c|c|c|c|}
\hline \multicolumn{6}{|c|}{ Table 1: Clinical details of the 5 children with Aripiprazole-Induced Seizures. } \\
\begin{tabular}{|c|c|c|c|c|c|c|} 
No & Age & Sex & $\begin{array}{c}\text { Number of } \\
\text { AEDs }\end{array}$ & $\begin{array}{c}\text { Seizure } \\
\text { Provocation }\end{array}$ & $\begin{array}{c}\text { Seizure } \\
\text { worsening }\end{array}$ & $\begin{array}{c}\text { Status } \\
\text { epilepticus }\end{array}$ \\
\hline 1. & $6 y$ & M & 2 & - & + & - \\
\hline 2. & $7.5 y$ & F & 1 & + & - & + \\
\hline 3. & $8 y$ & M & 2 & + & - & - \\
\hline 4. & $10 y$ & M & 2 & + & - & - \\
\hline 5. & $11.5 y$ & F & 2 & - & + & - \\
\hline
\end{tabular} \\
\hline
\end{tabular}


To conclude, seizure provocation or worsening seizure control is not uncommon following the introduction of Aripiprazole in autistic children with controlled epilepsy. Although the risk is low, parents should be warned and advised on what to do, particularly in the first month of therapy.

\section{References}

1. Ditcher AM, Brodie MJ. New antiepileptic drugs: a review. $\mathrm{N}$ Engl J Med. 1996; 334: 1583-1590.

PubMed: https://www.ncbi.nlm.nih.gov/pubmed/8628341

2. Velíšková J, Silverman JL, Benson M, Lenck-Santini PP. Autistic traits in epilepsy models: Why, when and how? Epilepsy Res. 2018; 144: 62-70. PubMed: https://www.ncbi.nlm.nih.gov/pubmed/29783181

3. Kumar B, Prakash A, Sewal RK, Medhi B, Modi M. Drug therapy in autism: a present and future perspective. Pharmacol Rep. 2012; 64: 1291-1304. PubMed: https://www.ncbi.nlm.nih.gov/pubmed/23406740

4. Parmeggiani L, Belmonte A, Ferrari AR, Perucca E, Guerrini R. Add-on lamotrigine treatment in children and young adults with severe partial epilepsy: an open, prospective, long-term study. J Child Neurol. 2000;
15: 671-674.

PubMed: https://www.ncbi.nlm.nih.gov/pubmed/11063081

5. Greenaway M, Elbe D. Focus on aripiprazole: a review of its use in child and adolescent psychiatry. J Can Acad Child Adolesc Psychiatry. 2009; 18: 250-260.

PubMed: https://www.ncbi.nlm.nih.gov/pubmed/19718428

6. ThabetFI, Sweis RT, Joseph SA. Aripiprazole-induced seizure in a 3-yearold child: a case report and literature review. Clin Neuropharmacol. 2013: 36; 29-30.

PubMed: https://www.ncbi.nlm.nih.gov/pubmed/23334073

7. Bolton PF, Carcani-Rathwell I, Hutton J, Goode $S$, Howlin $P$, et al. Epilepsy in autism: features and correlates. Br J Psychiatry. 2011; 198: 289-294.

PubMed: https://www.ncbi.nlm.nih.gov/pubmed/21972278

8. Strasser L, Downes M, Kung J, Cross JH, Haan MD. Prevalence and risk factors for autism spectrum disorder in epilepsy: a systematic review and meta-analysis. Dev Med Child Neurol. 2018; 60: 19-29. PubMed: https://www.ncbi.nlm.nih.gov/pubmed/29119560

9. Wu CS, Wang SC, Yeh IJ, Liu SK. Comparative risk of seizure with use of first- and second-generation antipsychotics in patients with schizophrenia and mood disorders. J Clin Psychiatry. 2016; 77: e573-579. PubMed: https://www.ncbi.nlm.nih.gov/pubmed/27249081 